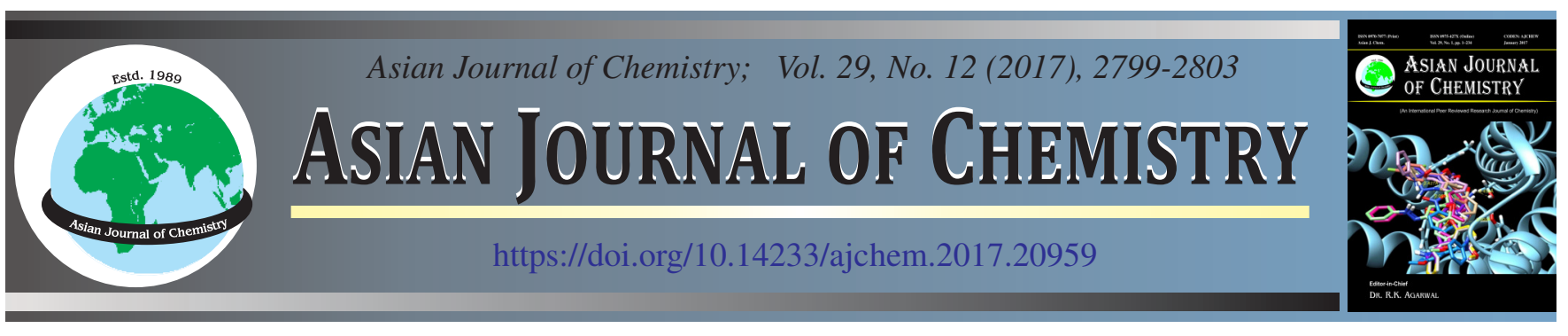

\title{
Preparation and Comparison of Magnetic Nanoparticles and Magnetic Nanoparticles Doped with Cobalt for Photodegradation of Methyl Orange
}

EMAN AlZAHRANi

Department of Chemistry, Faculty of Science, Taif University, Taif, Kingdom of Saudi Arabia

Corresponding author: E-mail: em-s-z@hotmail.com

\begin{abstract}
This paper describes a study in which magnetic nanoparticles were fabricated via co-precipitation approach. These nanoparticles were then coated with cobalt as a means of enhancing their photocatalytic activity. A variety of different instruments were used to characterize the magnetic nanoparticles including transmission electron microscopy, X-ray diffraction analysis, and scanning electron microscope. They were then tested to determine the extent to which they could effectively degrade harmful dyes in the form of was methyl orange under UV lamp irradiation $(365 \mathrm{~nm}$ ). The performance of standard magnetic nanoparticles was compared with those coated with cobalt in terms of removal of methyl orange to determine the extent to which Co-doped magnetic nanoparticles can more effectively facilitate the photocatalytic degradation of methyl orange in comparison to standard magnetic nanoparticles.
\end{abstract}

Keywords: Co-doped $\mathrm{Fe}_{3} \mathrm{O}_{4}$, Methyl orange, Nanoparticles, Photocatalyst, Photocatalytic degradation.

\section{INTRODUCTION}

Environmental pollution is one of the biggest issues to plague contemporary society. One pollutant that is of particular concern to humanity is that results from the use of synthetic dyes. Synthetic dyes are produced for a variety of industrial purposes including adding colour to paper, wool, printed material, textiles and leather. It is also used in a range of chemical processes [1,2]. Researchers have calculated that between 1 and 10 $\%$ of synthetic dyes that are used in industrial applications are ultimately released into the environment in the form of dyed wastewater [3]. These chemicals are composed of coal-tar based hydrocarbons such as anthracene, benzene, naphthalene, toluene and xylene [4-9]. These hydrocarbons give the dyes a complex aromatic structure that is problematic to decolourize. The wastewater that is released into the environment is toxic and carcinogenic to humans [10-12]. As such, there is a pressing need to identify processes by which synthetic dyes can be removed from wastewater before it is released to the environment [13-17].

A range of different approaches has been tested as potential methods of removing waste from industrial wastewater. These include adsorption, electroflotation, nanofiltration and ozonation and they have all been found to exhibit certain capabilities that may facilitate the process by which dyes are removed from water [18-20]. Of the various methods that are available, adsorption has been found to be the most effective approach by which wastewater can be purified [21-23] because it is simple to perform and is not sensitive to toxic substances. One material that can be utilized within an adsorption approach to removing harmful dyes from wastewater is activated carbon. This is often beneficial because it offers a high surface area [24-27]. However, one issue associated with the use of activated carbon is that it is of high cost. Alternative materials include lime, ferric salt and alum. While these materials are low-cost than activated carbon but have some disadvantages [28-31].

A large amount of the researches based on different methods of developing and synthesizing nanoparticles are reported in the literature [32-35]. Magnetic nanoparticles are essentially nanoparticles that can be manipulated using a magnetic field. They have attracted the interest of many researchers due to their large surface area, lack of toxicity, high thermal stability, strong magnetic properties and high mechanical strength [36-38]. Further advantages of magnetic nanoparticles are that they are costeffective, exhibit high separation efficiency, can be quickly and easily prepared and facilitate a straight-forward operational process. Magnetic nanoparticles have been successfully applied in a range of applications [39-42].

Over the past ten years, magnetic nanoparticles have been successfully employed to address a range of environmental issues. Scientists are particularly attracted to magnetic nanoparticles because it is easy to optimize their size and morphology and rapid magnetic separation when exposed to an external magnetic field [43-46]. The co-precipitation approach, in particular, represents asimple and efficient method by which magnetic 
nanoparticles can be fabricated from aqueous salt solutions in an alkaline medium under an inert atmosphere at either room or elevated temperatures. One of the biggest advantages of the co-precipitation approach is that it can generate fine and stoichiometric particles of both single and multicomponent metal oxides [47-51].

To enhance the chemical properties of magnetic nanoparticles and fabricate nanoparticles that can be successfully utilized for a range of different purposes, it is essential that the surfaces of magnetic nanoparticles can be modified to create functional groups [52,53]. One problem that is commonly associated with magnetic nanoparticles is that charged carriers can recombine within nanoseconds. One method of overcoming this is by doping magnetic nanoparticles. This traps and, consequently, transfers the photoexcited electrons onto the photocatalyst surface, thereby reducing the recombination of charged carriers [54,55].

A literature review revealed that limited studies have examined the impact that doped magnetic nanoparticles have on the process by which harmful dyes are removed from wastewater via photodegradation. As such, the aim of the existing research was to employ the co-precipitation method to fabricate magnetic nanoparticles before doping these magnetic nanoparticles with cobalt. The characterizations of magnetic nanoparticles and Co-doped magnetic nanoparticles were performed using transmission electron microscopy, X-ray diffraction and scanning electron microscopy. The magnetic nanoparticles and Co-doped magnetic nanoparticles were then tested to determine the extent to which they facilitated the photodegradation of dyes in the presence of ultraviolet light.

\section{EXPERIMENTAL}

Methyl orange and iron(II) sulphate $\left(\mathrm{FeSO}_{4} \cdot 7 \mathrm{H}_{2} \mathrm{O}, 98 \%\right)$, m.w. $=151.91 \mathrm{~g} \mathrm{~mol}^{-1}$, sodium nitrite $(99 \%)$ were acquired from Sigma-Aldrich (Nottingham, UK). Sodium hydroxide was purchased from Loba Chemie Pvt. Ltd. (Mumbai, India). Hydrochloric acid and cobalt(II) chloride (99.85\%) were purchased from Acros Organics (Loughborough, UK). Cylindrical rod magnets ( $40 \mathrm{~mm}$ diameter $\times 40 \mathrm{~mm}$ thickness), which were employed for settlement of magnetic nanoparticles, acquired from Magnet Expert Ltd. (Tuxford, UK). Purified water was used throughout the preparation of the reagents and solutions.

The magnetic stirrer and heater were acquired from Fisher Scientific Co. Ltd. (Shanghai, China). The oven was from Memmert (Nuremberg, Germany). X-ray diffraction patterns were obtained using a Bruker diffractometer D8-ADVANCE with CuK $\alpha 1$ radiation (Coventry, UK). Transmission electron microscope (TEM) was acquired from JEOL Ltd. (Welwyn Garden City, UK). The scanning electron microscope (SEM) was purchased from JEOL-JSM 6390 LA Analytical (Tokyo, Japan). The UV lamp $(\lambda=365 \mathrm{~nm})$ was acquired from Spectronic Analytical Instruments (Leeds,UK). The UV-visible spectrophotometer was from Thermo Scientific GENESYS 10S (Toronto, Canada).

Preparation of $\mathrm{Fe}_{3} \mathrm{O}_{4}$ nanoparticles: $\mathrm{The}_{\mathrm{Fe}} \mathrm{O}_{4}$ magnetic nanoparticles were fabricated according to the known method [56]. Sodium nitrate $(2 \mathrm{~g})$ and $\mathrm{FeSO}_{4} \cdot 7 \mathrm{H}_{2} \mathrm{O}(3.3 \mathrm{~g})$ were dissolved in $50 \mathrm{~mL}$ of distilled water. Following that $20 \mathrm{~mL}$ of $\mathrm{NaOH}$ solution $(2.5 \mathrm{M})$ was added to the mixture and heated to $80{ }^{\circ} \mathrm{C}$.
The resulting reaction was maintained at $80^{\circ} \mathrm{C}$ under constant stirring to make sure the nanoparticle crystals had reached full growth. After $30 \mathrm{~min}$, the suspension was cooled to room temperature and repeatedly washed with distilled water to remove unreacted chemicals. An external magnet was employed to extract the resulting $\mathrm{Fe}_{3} \mathrm{O}_{4}$ magnetic nanoparticles. These were also washed with distilled water and ethanol to remove any impurities. The nanoparticles were then dried overnight in an oven at $50{ }^{\circ} \mathrm{C}$.

Preparation of Co-doped $\mathrm{Fe}_{3} \mathrm{O}_{4}$ nanoparticles: The Codoped magnetic nanoparticles were fabricated using the approach previously described [57]. Cobalt(II) chloride was added to an aqueous solution of $\mathrm{FeSO}_{4} \cdot 7 \mathrm{H}_{2} \mathrm{O}$ and $\mathrm{NaNO}_{3}$ followed by the addition of $\mathrm{NaOH}$ solution $(2.5 \mathrm{M})$ dropwise under continuous stirring $(700 \mathrm{rpm})$ until the $\mathrm{pH}$ of solution reached 11. It was then acidified with $(10.8 \mathrm{~N}) \mathrm{HCl}$ to reach a $\mathrm{pH}$ of 3 . The precipitate of $\mathrm{Co}$-doped $\mathrm{Fe}_{3} \mathrm{O}_{4}$ magnetic nanoparticles was then collected using the same process as that outlined for $\mathrm{Fe}_{3} \mathrm{O}_{4}$ nanoparticles.

Structural analysis and phase identification of magnetic nanoparticles were conducted using XRD in combination with $\mathrm{CuK} \alpha 1$ radiation in the $2 \theta$ range from $20^{\circ}$ to $70^{\circ}$. SEM and TEM analyses were then employed to identify the morphology of fabricated magnetic nanoparticles both before and after Codoping. A drop of well-dispersed nanoparticle dispersion was placed onto the amorphous carbon-coated 200-mesh copper grid and left to dry at ambient temperature. The grid was subsequently scanned.

Evaluation of photocatalytic activity: To investigate the ability of Co-doped $\mathrm{Fe}_{3} \mathrm{O}_{4}$ nanoparticles to remove dye, methyl orange dye was employed as a probe molecule. The degradation reactions that were evaluated in this research were conducted using the following procedure. First, $100 \mathrm{~mL}$ of the aqueous dye solution $\left(4 \times 10^{-4} \mathrm{M}\right)$ was placed into a cylindrical glass container before $50 \mathrm{mg}$ of Co-doped $\mathrm{Fe}_{3} \mathrm{O}_{4}$ nanoparticles was added and the solution was magnetically stirred at $600 \mathrm{rpm}$ over a period of $1 \mathrm{~h}$ in a dark room to achieve an adsorption-desorption equilibrium between dye and photocatalyst. The catalytic reaction was then triggered using a source of irradiation. Again, constant magnetic stirring was maintained throughout the reaction process while $2 \mathrm{~mL}$ of suspension was extracted from the solution after every $30 \mathrm{~min}$. A UV-visible spectrophotometer at a wavelength range of 350-800 nm was employed to analyze the concentration of the residual dye $[58,59]$ using eqn. 1 :

$$
\mathrm{D}(\%)=\frac{\mathrm{C}_{0}-\mathrm{C}}{\mathrm{C}_{0}} \times 100=\frac{\mathrm{A}_{0}-\mathrm{A}}{\mathrm{A}_{0}} \times 100
$$

where $\mathrm{C}_{\mathrm{o}}$ and $\mathrm{C}$ are the concentration of the dye at the start of the process and any time thereafter, respectively, $\mathrm{A}_{\mathrm{o}}$ and $\mathrm{A}$ are the absorbance of methyl orange solution at $465 \mathrm{~nm}$ wavelength at the time of initiation and any time thereafter, respectively [23].

\section{RESULTS AND DISCUSSION}

Preparation of magnetic nanoparticles and Co-doped magnetic nanoparticles: Magnetic nanoparticles were selected for this research because they are relatively straight-forward to fabricate and can be readily separated from the solution using 
a strong external magnet $[38,59,60]$. A standard precipitation technique that utilized an aqueous salt solution in an alkaline medium was employed to fabricate the magnetic nanoparticles. This particular approach was selected on the basis that it represents a common and efficient approach to fabricate magnetic nanoparticles $[40,61,62]$. The method involved mixing $\mathrm{FeSO}_{4} \cdot 7 \mathrm{H}_{2} \mathrm{O}$ with $\mathrm{NaNO}_{3}$ in distilled water. The $\mathrm{Fe}_{3} \mathrm{O}_{4}$ nanoparticles were completely precipitated under alkaline conditions in $\mathrm{NaOH}$ solution $(2.5 \mathrm{M})$ which was vigorously stirred at $80^{\circ} \mathrm{C}$. Iron(II) hydroxide was formed when $\mathrm{NaOH}$ solution was added to the $\mathrm{FeSO}_{4}$. This was subsequently oxidized to produce $\mathrm{Fe}_{3} \mathrm{O}_{4}$ nanoparticle $[61,63,64]$. These nanoparticles were extracted from the reaction solution using a permanent magnetic field and then washed with purified water to remove excess ions.

X-ray diffraction: A diffractometer with high-intensity $\mathrm{CuK} \alpha 1$ radiation $(\lambda=1.54065 \AA)$ was used to perform the measurements from $10^{\circ}$ to $70^{\circ}[60]$. The XRD patterns of naked and Co-doped magnetic nanoparticles are shown in Fig. 1. Six characteristic peaks for $\mathrm{Fe}_{3} \mathrm{O}_{4}$ were observed at $30^{\circ}, 35^{\circ}, 37^{\circ}, 43^{\circ}, 53^{\circ}$, $57^{\circ}$ and $62^{\circ}$. These corresponds to $220,311,222,400,422,511$ and 440 crystal planes of pure $\mathrm{Fe}_{3} \mathrm{O}_{4}$ with a cubic spinel structure of magnetite $[63,65,66]$. All the main peaks can be indexed undisputedly as pure $\mathrm{Fe}_{3} \mathrm{O}_{4}$ of spinel structure (space group: Fd-3 m), which is strongly aligned with the standard data (JCPDS card 19-0629). Interestingly, none of the other phases were identified. This indicates that the cobalt was only deposited on the surface of crystals.

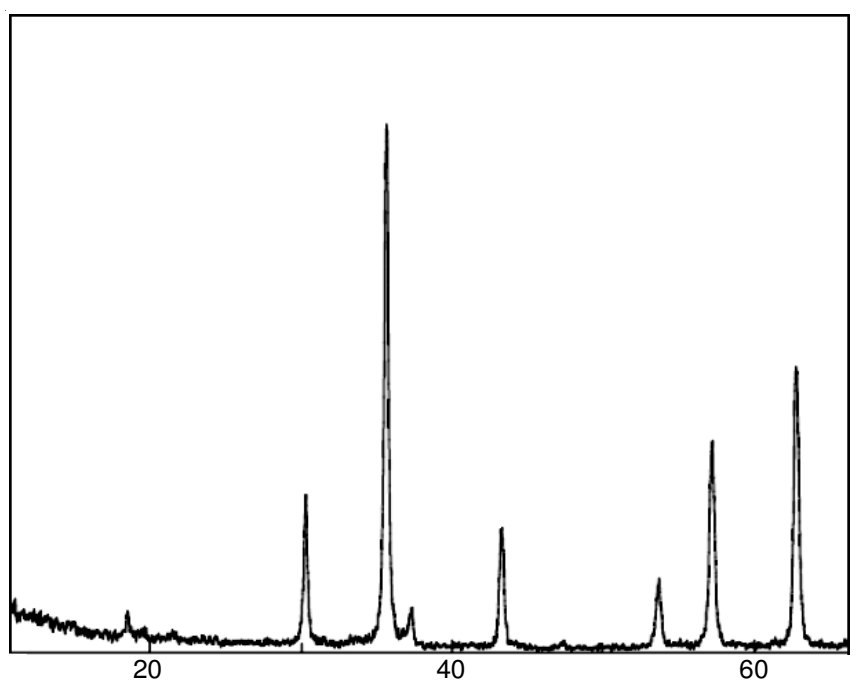

Fig. 1. XRD pattern of $\mathrm{Fe}_{3} \mathrm{O}_{4}$ nanoparticles

Scanning electron microscopy: SEM analysis was employed to examine the morphology of both magnetic nanoparticles and Co-doped magnetic nanoparticles. The SEM images of naked magnetic nanoparticles and Co-doped magnetic nanoparticles that were fabricated using the co-precipitation approach are shown in Fig. 2. As can be observed, naked magnetic nanoparticles consisted of non-uniform nanoparticles that exhibited an irregular crystalline structure. This indicates that magnetic nanoparticles were formed of an agglomeration of a large number of ultrafine particles. No major difference between the morphology of naked magnetic nanoparticles and Co-doped magnetic nanoparticles was detectable. This indicated that

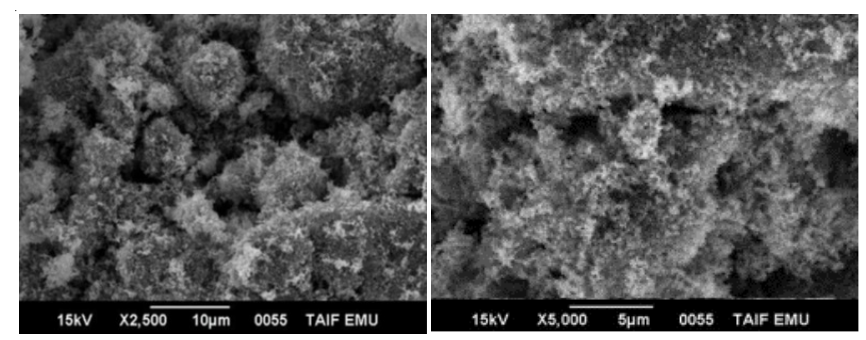

Fig. 2. SEM micrographs of naked MNPs (left) and Co-doped MNPs (right)

Co-doped magnetic nanoparticles did not change the crystal morphology of magnetic nanoparticles. This finding is agreed with Song et al. [57].

Transmission electron microscopy: Fig. 3 presents the TEM images of naked magnetic nanoparticles and Co-doped magnetic nanoparticles. While both types of magnetic nanoparticles exhibited a crystalline structure which consisted of identifiable shapes. The TEM analyses indicated that some differences were observed between naked and Co-doped magnetic nanoparticles, specifically, Co-doped magnetic nanoparticles appeared to be darker and more compact than naked magnetic nanoparticles. This indicated that Co-doped magnetic nanoparticles had a higher density.

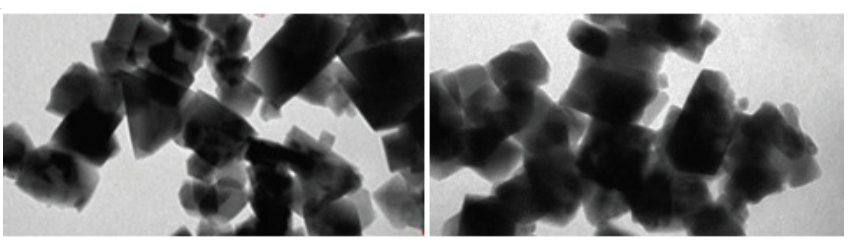

Fig. 3. TEM micrographs of naked $\mathrm{Fe}_{3} \mathrm{O}_{4}$ nanoparticles (left) and $\mathrm{Co}$-doped $\mathrm{Fe}_{3} \mathrm{O}_{4}$ nanoparticles (right)

Comparison between magnetic nanoparticles and Codoped magnetic nanoparticles

Photodegradation activity: The photodegradation activity of magnetic nanoparticles in comparison to Co-doped magnetic nanoparticles was evaluated by adding $50 \mathrm{mg}$ of catalyst to $100 \mathrm{~mL}$ of methyl orange dye solution $\left(4 \times 10^{-4} \mathrm{M}\right)$. The suspension was magnetically stirred at a rate of $600 \mathrm{rpm}$ throughout the experiment. It was stored in dark conditions for a period of $1 \mathrm{~h}$ to attain adsorption-desorption equilibrium before being irradiated using UV light (365 nm). After every $30 \mathrm{~min}$ interval of the irradiation time (0-300 $\mathrm{min}$ ), an aliquot $(2 \mathrm{~mL})$ was extracted from the suspension. The observations revealed that the intense orange colour of the initial solution gradually disappeared until the point at which it becomes colourless. This indicated that the dye had been successfully degraded under UV light irradiation.

The absorbance of methyl orange was measured using a UV-Vis spectrophotometer as a means of evaluating changes in orange colour concentration. The $465 \mathrm{~nm}$ band was used to monitor the effect of photocatalysts on methyl orange degradation. Fig. 4 indicated that the UV-visible exhibited a timedependent absorption spectrum during the photocatalytic reaction of methyl orange. In addition, the absorption spectrum maximum of methyl orange steadily decreased. This observation indicates that the extended aromatic methyl orange was absorbed 

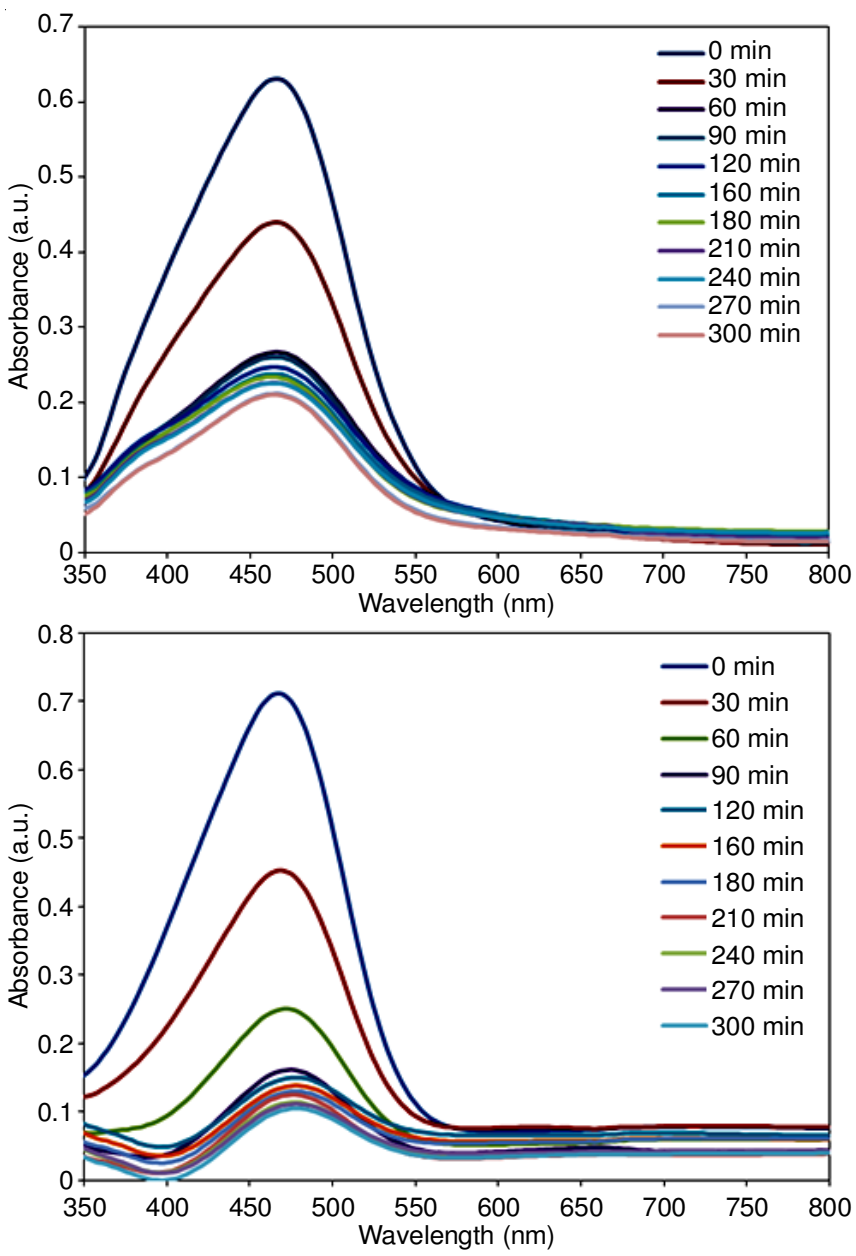

Fig. 4. Absorption spectrum of methyl orange in the presence of $50 \mathrm{mg}$ of naked magnetic nanoparticles (top) and Co-doped magnetic nanoparticles (bottom) at different time intervals (0-300 $\mathrm{min})$ following exposure to UV light $(365 \mathrm{~nm})$ and temperature $25 \pm 0.1^{\circ} \mathrm{C}$ at 350 $800 \mathrm{~nm}$

at $465 \mathrm{~nm}$, creating a mono-substituted aromatics. Finally, methyl orange started to degrade.

Reuse of photocatalyst: After methyl orange had been degraded, Co-doped magnetic nanoparticles were separated from the solution using a magnet. The magnetic nanoparticles were then washed with distilled water and reused to degrade a further sample of methyl orange dye solution. As can be observed in Fig. 5, no significant loss in the photodegradation activity of Co-doped magnetic nanoparticles was observed over three tests. These results confirmed that Co-doped magnetic nanoparticles are not photocorroded during the process by which the dye is photocatalytically oxidized.

\section{Conclusion}

This work described the process by which magnetic nanoparticles were successfully fabricated and then doped with cobalt. The morphology of magnetic nanoparticles before and after doped with cobalt was characterized using SEM and TEM analysis. The XRD revealed that the structures exhibited the patterns that were typical of $\mathrm{Fe}_{3} \mathrm{O}_{4}$. The experimental results showed that Co-doped magnetic nanoparticles more effectively degraded methyl orange photocatalytically than naked magnetic nanoparticles. In addition, after dye had been treated, the fabricated materials were easily recovered through

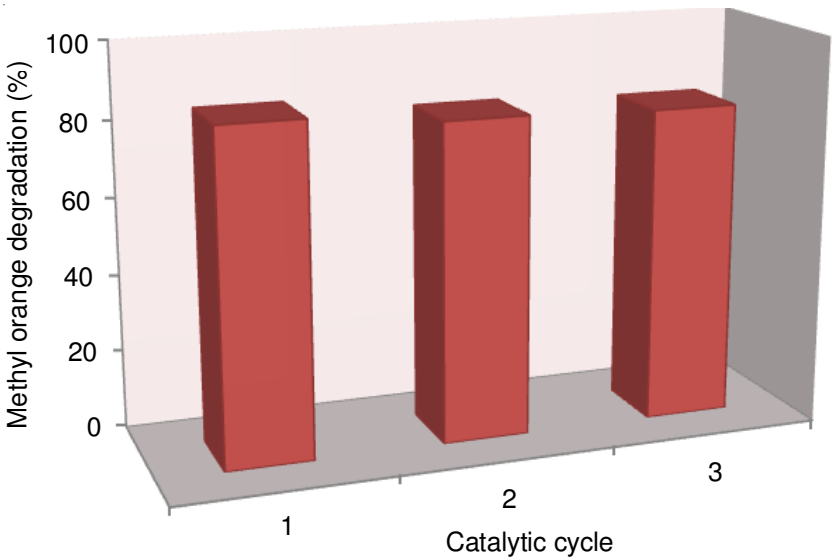

Fig. 5. Decomposition percentage of methyl orange vs. time as a function of the cycle number (Co-doped magnetic nanoparticles)

the use of an external magnet. The results of this study indicated that UV/Co-doped magnetic nanoparticles can be effectively utilized to remove methyl orange from industrial wastewater.

\section{ACKNOWLEDGEMENTS}

The author acknowledges the research grant provided by Deanship of Scientific Research at Taif University, Kingdom of Saudi Arabia (Grant No. 4741-437-1).

\section{REFERENCES}

1. E. Gurr, Synthetic Dyes in Biology, Medicine and Chemistry, Elsevier (2012).

2. Shahid-ul-Islam and F. Mohammad, Ind. Eng. Chem. Res., 54, 3727 (2015);

https://doi.org/10.1021/acs.iecr.5b00524.

3. X. Zhang, F. Wu and N. Deng, J. Hazard. Mater., 185, 117 (2011); https://doi.org/10.1016/j.jhazmat.2010.09.005.

4. M.B. Hasan, Master of Science Thesis, Adsorption of Reactive Azo Dyes on Chitosan/Oil Palm Ash Composite Adsorbent: Batch and Continuous Studies, Universiti Sains Malaysia (2008).

5. I. Tan, A. Ahmad and B. Hameed, J. Hazard. Mater., 153, 709 (2008); https://doi.org/10.1016/j.jhazmat.2007.09.014.

6. I. Tan, A.L. Ahmad and B. Hameed, J. Hazard. Mater., 154, 337 (2008); https://doi.org/10.1016/j.jhazmat.2007.10.031.

7. R. Gong, Y. Sun, J. Chen, H. Liu and C. Yang, Dyes Pigments, 67, 175 (2005); https://doi.org/10.1016/j.dyepig.2004.12.003.

8. C. Namasivayam and D. Kavitha, Dyes Pigments, 54, 47 (2014); https://doi.org/10.1016/S0143-7208(02)00025-6.

9. F. Shakeel, N. Haq, F.K. Alanazi and I.A. Alsarra, Ind. Eng. Chem. Res., 53, 1179 (2013); https://doi.org/10.1021/ie403271t.

10. A.K. Verma, R.R. Dash and P. Bhunia, J. Environ. Manage., 93, 154 (2012); https://doi.org/10.1016/j.jenvman.2011.09.012.

11. H. Kim, S. Lee, S. Ryu and H.T. Choi, Appl. Biochem. Biotechnol., 166, 159 (2012);

https://doi.org/10.1007/s12010-011-9412-y.

12. Y. Patel and A. Gupte, Water Environ. Res., 87, 242 (2015); https://doi.org/10.2175/106143015X14212658613190.

13. S. Mondal, Environ. Eng. Sci., 25, 383 (2008); https://doi.org/10.1089/ees.2007.0049.

14. G. Crini, Bioresour. Technol., 97, 1061 (2006); https://doi.org/10.1016/j.biortech.2005.05.001.

15. S. Khattri and M. Singh, J. Hazard. Mater., 167, 1089 (2009); https://doi.org/10.1016/j.jhazmat.2009.01.101.

16. A. Srinivasan and T. Viraraghavan, J. Environ. Manage., 91, 1915 (2010); https://doi.org/10.1016/j.jenvman.2010.05.003.

17. A. Mittal, V. Thakur, J. Mittal and H. Vardhan, Desalination Water Treat., 52, 227 (2014);

https://doi.org/10.1080/19443994.2013.785030. 
18. U. Rott, J. Environ. Sci. Health A, 38, 1629 (2003); https://doi.org/10.1081/ESE-120021485.

19. Z. Houshyar, A.B. Khoshfetrat and E. Fatehifar, Chem. Eng. J., 191, 59 (2012); https://doi.org/10.1016/j.cej.2012.02.053

20. D. Ghernaout, C. Benblidia and F. Khemici, Desalination Water Treat., 54, 3328 (2014); https://doi.org/10.1080/19443994.2014.90774

21. A. Maljaei, M. Arami and N.M. Mahmoodi, Desalination, 249, 1074 (2009);

https://doi.org/10.1016/j.desal.2009.05.016

22. A. Aouni, C. Fersi, M. Ben Sik Ali and M. Dhahbi, J. Hazard. Mater. 168, 868 (2009); https://doi.org/10.1016/j.jhazmat.2009.02.112.

23. M. Rafatullah, O. Sulaiman, R. Hashim and A. Ahmad, J. Hazard. Mater., 177, 70 (2010); https://doi.org/10.1016/j.jhazmat.2009.12.047.

24. M. Purkait, A. Maiti, S. DasGupta and S. De, J. Hazard. Mater, 145, 287 (2007); https://doi.org/10.1016/j.jhazmat.2006.11.021.

25. P. Malik, J. Hazard. Mater, 113, 81 (2004); https://doi.org/10.1016/j.jhazmat.2004.05.022.

26. V. Gupta, B. Gupta, A. Rastogi, S. Agarwal and A. Nayak, J. Hazard. Mater., 186, 891 (2011); https://doi.org/10.1016/j.jhazmat.2010.11.091.

27. A. Ahmad, A. Idris and B. Hameed, Desalination Water Treat., 52, 248 (2014); https://doi.org/10.1080/19443994.2013.794012.

28. W. Chu, Water Res., 35, 3147 (2001); https://doi.org/10.1016/S0043-1354(01)00015-X

29. T. Robinson, G. McMullan, R. Marchant and P. Nigam, Bioresour. Technol., 77, 247 (2001); https://doi.org/10.1016/S0960-8524(00)00080-8.

30. V.K. Gupta, I. Ali, Suhas and D. Mohan, J. Colloid Interface Sci., 265 , 257 (2003); https://doi.org/10.1016/S0021-9797(03)00467-3.

31. X. Cai, B. Han, S. Deng, Y. Wang, C. Dong, Y. Wang and I. Djerdj, CrystEngComm, 16, 7761 (2014); https://doi.org/10.1039/C4CE00899E.

32. Y. Li and G.A. Somorjai, Nano Lett., 10, 2289 (2010); https://doi.org/10.1021/nl101807g.

33. Y. Zhang and C. Erkey, J. Supercrit. Fluids, 38, 252 (2006); https://doi.org/10.1016/j.supflu.2006.03.021.

34. E. Alzahrani, World J. Nano Sci. Eng., 5, 10 (2015); https://doi.org/10.4236/winse.2015.51002.

35. E. Alzahrani and K. Welham, Int. J. Basic Appl. Sci., 3, 392 (2014); https://doi.org/10.14419/ijbas.v3i4.3358.

36. M. Wierucka and M. Biziuk, Trends Analyt. Chem., 59, 50 (2014); https://doi.org/10.1016/j.trac.2014.04.007.

37. M.M. El-Hammadi and J.L. Arias, Expert Opin. Ther. Pat., 25, 691 (2015); https://doi.org/10.1517/13543776.2015.1028358.

38. S. Majidi, F.Z. Sehrig, M. Samiei, M. Milani, E. Abbasi, K. Dadashzadeh and A. Akbarzadeh, Artif. Cells Nanomed. Biotechnol., Article ID 1014093 (2015); https://doi.org/10.3109/21691401.2015.1014093

39. C. Sun, J.S. Lee and M. Zhang, Adv. Drug Deliv. Rev., 60, 1252 (2008); https://doi.org/10.1016/j.addr.2008.03.018.

40. V.I. Shubayev, T.R. Pisanic II and S. Jin, Adv. Drug Deliv. Rev., 61, 467 (2009); https://doi.org/10.1016/j.addr.2009.03.007.

41. E. Alzahrani, A. Sharfalddin and M. Alamodi, Adv. Nanoparticles, 4, 53 (2015); https://doi.org/10.4236/anp.2015.42007.

42. E. Alzahrani, Int. J. Adv. Sci. Technical Res., 4, 755 (2014).
43. W. Yantasee, C.L. Warner, T. Sangvanich, R.S. Addleman, T.G. Carter, R.J. Wiacek, G.E. Fryxell, C. Timchalk and M.G. Warner, Environ. Sci. Technol., 41, 5114 (2007); https://doi.org/10.1021/es0705238.

44. Y. Cedeño-Mattei, O. Perales-Perez, M. Tomar, F. Roman, P. Voyles and W. Stratton, J. Appl. Phys., 103, 1 (2008); https://doi.org/10.1063/1.2838215.

45. C. Yang, J. Xing, Y. Guan, J. Liu and H. Liu, J. Alloys Comp., 385, 283 (2004); https://doi.org/10.1016/j.jallcom.2004.03.137.

46. D. Wang and D. Astruc, Chem. Rev., 114, 6949 (2014); https://doi.org/10.1021/cr500134h.

47. A.H. Lu, E.L. Salabas and F. Schüth, Angew. Chem. Int. Ed., 46, 1222 (2007); https://doi.org/10.1002/anie.200602866

48. S. Laurent, D. Forge, M. Port, A. Roch, C. Robic, L. Vander Elst and R.N. Muller, Chem. Rev., 108, 2064 (2008); https://doi.org/10.1021/cr068445e.

49. K. Woo, J. Hong, S. Choi, H.-W. Lee, J.-P. Ahn, C.S. Kim and S.W. Lee, Chem. Mater., 16, 2814 (2004); https://doi.org/10.1021/cm049552x.

50. A.S. Teja and P.-Y. Koh, Prog. Cryst. Growth Charact. Mater., 55, 22 (2009); https://doi.org/10.1016/j.pcrysgrow.2008.08.003.

51. M.H. Ramezanzadeh, M. Seifi, H. Hekmatara, Z. Zarnegar and M.H. Loghmani, Synth. React. Inorg. Met.-Org. Nano-Met. Chem., 45, 392 (2015); https://doi.org/10.1080/15533174.2013.790432.

52. W. Wu, Q. He and C. Jiang, Nanoscale Res. Lett., 3, 397 (2008); https://doi.org/10.1007/s11671-008-9174-9.

53. S. Mallakpour and M. Madani, Prog. Org. Coat., 86, 194 (2015); https://doi.org/10.1016/j.porgcoat.2015.05.023.

54. A. Sclafani and J.-M. Herrmann, J. Photochem. Photobiol. Chem., 113, 181 (1998); https://doi.org/10.1016/S1010-6030(97)00319-5.

55. M.J. Kale, T. Avanesian and P. Christopher, ACS Catal., 4, 116 (2014); https://doi.org/10.1021/cs400993w.

56. E. Alzahrani, Am. J. Anal. Chem., 8, 95 (2017); https://doi.org/10.4236/ajac.2017.81008.

57. X.C. Song, Y.F. Zheng and H.Y. Yin, J. Nanopart. Res., 15, 1 (2013)

58. E. Alzahrani, Curr. Anal. Chem., 12, 465 (2016); https://doi.org/10.2174/1573412912666160104234348.

59. A. Sharfalddin, E. Alzahrani and M. Alamoudi, Am. Chem. Sci. J, 13, 1 (2016); https://doi.org/10.9734/ACSJ/2016/23648.

60. E. Alzahrani, Int. J. Anal. Chem., Article ID 797606 (2015); https://doi.org/10.1155/2015/797606.

61. J. Fan, Y. Guo, J. Wang and M. Fan, J. Hazard. Mater., 166, 904 (2009); https://doi.org/10.1016/j.jhazmat.2008.11.091.

62. A.A. Jalil, S. Triwahyono, S.H. Adam, N.D. Rahim, M.A.A. Aziz, N.H.H. Hairom, N.A.M. Razali, M.A. Abidin and M.K.A. Mohamadiah, J. Hazard. Mater., 181, 755 (2010); https://doi.org/10.1016/j.jhazmat.2010.05.078.

63. M.C. Das, H. Xu, Z. Wang, G. Srinivas, W. Zhou, Y.-F. Yue, V.N. Nesterov, G. Qian and B. Chen, Chem. Commun., 47, 11715 (2011); https://doi.org/10.1039/c1cc12802g.

64. R. Kumar, G. Kumar and A. Umar, Mater. Lett., 97, 100 (2013); https://doi.org/10.1016/j.matlet.2013.01.044.

65. S. Al-Qaradawi and S.R. Salman, J. Photochem. Photobiol. Chem., 148, 161 (2002); https://doi.org/10.1016/S1010-6030(02)00086-2.

66. I. Arabatzis, T. Stergiopoulos, M. Bernard, D. Labou, S. Neophytides and P. Falaras, Appl. Catal. B, 42, 187 (2003); https://doi.org/10.1016/S0926-3373(02)00233-3. 